\title{
SARS-CoV-2 pandemic in India: what might we expect?
}

\author{
Sneha Gautam ${ }^{1} \cdot$ Luc Hens $^{2,3}$
}

Received: 9 April 2020 / Accepted: 15 April 2020

(c) Springer Nature B.V. 2020

\section{Correspondence}

As of April 07, 2020, 1,348,628 cases of, including 74,834 deaths attributed to, novel Covid-19 (coronavirus disease 2019) had been informed worldwide (WHO 2019; Gautam and Trivedi 2020; aajtak.intoday.in/: 7 April, 2020). The incidence of known cases of novel coronavirus originated from Wuhan City of China has now been decreased by using prevention measures including strict social distancing; however, the pandemic SARS-CoV-2 (severe acute respiratory syndrome coronavirus 2 ) is continued transmitting in the developing countries including India.

In news media and documents, Government of India and Wikipedia reported the information of first affected human by SARS-CoV-2 in Kerala, India, which was recognized in late January 2020, originating from China. As expected, the reported case returned from China and transmitted the infection to all surrounding people with unprotected contact. As the proportion of asymptomatic SARS-CoV-2 cases to be reported is large, it is quite impossible that some asymptomatic persons went undetected. In this regard, Kagaya et al. (2020) estimated the asymptomatic proportion of the outbreak of about $18 \%$ from Diamond Princess Cruise Ship.

In India, as of April 07, 2020, 4421 cases of, including 114 deaths attributed to, novel Covid-19 (coronavirus disease 2019) were reported (Aajtak.intoday.in/: 7 April, 2020). The variation of number of affected persons can easily observed in India, where the highest and lowest cases have been reported from Maharashtra and Mizoram, respectively (Fig. 1).

According to Fig. 1, the highest number of cases have been reported in Maharashtra (15\%), Tamil Nadu (14\%), Delhi (13\%), and Kerala (10\%); however, it will be increased with time as the pandemic is still unravelling as the testing facilities are not broadly available across the country. On the other hand, few states of India fare better like Mizoram, Arunachal Pradesh, Manipur, etc. In contrast, Zhou et al. (2020) reported that the infection rate and risk of death are higher in older age persons. As per population census 2011, the states of India like Kerala (12.6\%), Goa (11.2\%) and Tamil Nadu (10.4\%) have maximum

Sneha Gautam

snehagautam@karunya.edu

1 Karunya Institute of Technology and Sciences, Coimbatore, Tamil Nadu 641114, India

2 Vlaamse Instelling voor Technologisch Onderzoek, 2400 Boeretang, Mol, Belgium

3 Department of Economics, Sumy State University, Sumy, Ukraine 


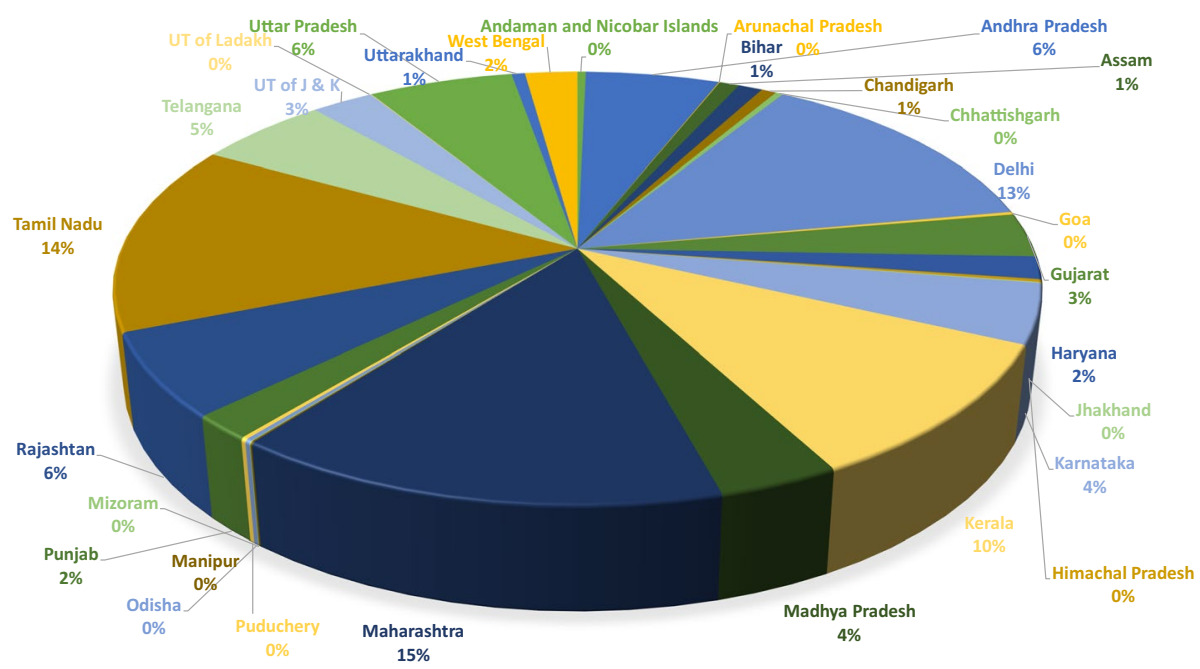

Fig. 1 Statewise information of reported cases. Source: Health Ministry of India

proportion of elderly people ( $\geq 65$ years) and might be the most vulnerable to this pandemic disease.

On March 22, 2020, The Lt. Governor of Delhi has notified the "Delhi Epidemic Diseases, Covid-19, Regulations, 2020" in New Delhi, where all hospitals to have flu corners to test for suspect cases, history of travelling to be recorded, and right to impose home or institution are the important silent features. On the other hand, all the states of India, applied the notification in which academic institutes will be closed until the next notification. Similarly, the government and private companies have asked their employees to work from home due to novel pandemic issue. The Prime Minister of India "Narendra Modi" announced a 21-day nationwide "Curfew/Lockdown", to minimize the impact of novel coronavirus, as he requested to Indian citizens with folded hands to practise strict social distancing.

To reduce the impact of novel coronavirus and its transmission, lockdown activities launched in whole country with restriction of human mobility and economic activities. However, to observe comprehensive air quality data in different places of India, it can be seen that these novel coronavirus disease countermeasures led to remarkable improvement in the concentration of air pollutants (https://aqicn.org/map/india/). According to WHO (2018), 4.2 million premature deaths were reported in the year of 2016 due to ambient air pollution. So, as per the air quality index is concerned, the enhancement in air quality of India now would significantly avert premature deaths due to air pollution on monthly/annually basis.

In India, many studies indicated that the transportation and movement of respiratory diseases depend on seasonal variation (Humbal et al. 2018, 2019, 2020). In this regard, we might expect that the effects of novel coronavirus will be decreased with higher temperature in summer, due to reduction in intrinsic transmissibility of the novel virus (Gautam and Trivedi 2020; Jung et al. 2009). Moreover, Ma et al. (2020) conducted the first study to identify the significant effects of meteorological parameters (i.e., temperature and relative humidity) on daily mortality due to Covid-19 in China. This study clearly mentioned that the daily mortality of Covid-19 is positively and negatively associated with temperature 
and relative humidity, respectively. It can be concluded that the warmer season (higher temperature during next few months) and lockdown activities will be key to reduce the exposure to novel coronavirus on humans. Close monitoring and real time data will be benefitted to predict and make sound public health decisions.

The world must prepare for the possibility that mitigation measures might fail because most of the countries are taking too much time to prevent or delay the spread of Covid-19. For example, SARS infects very small proportion of people around the world; however, many people will still become critically ill and need a better treatment or ICU care. The ICU departments should be developed in advance with rapid diagnosis and isolation, clinical management and infection prevention to control the incremental patients and optimize workflows. To prepare for a substantial increase in critical care bed capacity, three working bodies (i.e., state-national governments, hospital authorities and decision/policy makers) must come together and work with ICU practitioners. Scientists/professor/researchers have to address the important questions-"What remains a poorly understood disease". The focus on high-quality research work, real time data, practices based on real evidences, data availability based on open access, ethical integration in the point of extraordinary challenges and collaboration with chain like local to national and national to international will be important key factors to the success of this hard work.

These major viral pandemics all entail environmental, economic and social aspects which have only partially been described. This journal is open to research contributions on the sustainability aspects of Covid-19, SARS and related pandemics.

\section{References}

Gautam, S., \& Trivedi, U. K. (2020). Global implications of bio-aerosol in pandemic. Environmental Development and Sustainability. https://doi.org/10.1007/s10668-020-00704-2.

Humbal, C., Gautam, S., et al. (2019). Evaluating the colonization and distribution of fungal and bacterial bioaerosol in Rajkot, western India using multi-proxy approach. Air Quality Atmosphere and Health, 12(6), 693-704.

Humbal, C., Gautam, S., Joshi, S. K., \& Rajput, M. S. (2020). Spatial variation of airborne allergenic fungal spores in the ambient PM2.5-A study in Rajkot City, Western Part of India. In T. Gupta, et al. (Eds.), Measurement, analysis and remediation of environmental pollutants (pp. 199-209). Singapore: Springer. https://doi.org/10.1007/978-981-15-0540-9.

Humbal, C., Gautam, S., \& Trivedi, U. K. (2018). A review on recent progress in observations, and health effects of bioaerosols. Environmental International, 118, 189-193.

Jung, J. H., Lee, J. E., et al. (2009). Treatment of fungal bioaerosols by a high-temperature, short-time process in a continuous-flow system. Applied and Environmental Microbiology, 75, 2742-2749.

Kagaya, M. K., et al. (2020). Estimating the asymptomatic proportion of coronavirus disease 2019 (COVID19) cases on board the Diamond Princess cruise ship, Yokohama, Japan, 2020. Eurosurveillance Weekly, 2020(25), 2000180.

Ma, Y., Zhao, Y., Liu, J., et al. (2020). Effects of temperature variation and humidity on the death of COVID-19 in Wuhan, China. Science of the Total Environment, 724, 138226.

WHO. (2018). Ambient (outdoor) air pollution. Fact sheet. World Health Organization. https://www.who. int/en/news-room/factsheets/detail/ambient-(outdoor)-air-quality-and-health. Accessed 9 Apr 2020.

WHO. (2020). Coronavirus disease 2019 (COVID-19): Situation report-58. World Health Organization. Retrieved April 04, 2020, from https://www.who.int/docs/defaultsource/coronaviruse/situation-repor ts/20200318-sitrep-58-covid-19.pdf?sfvrsn=20876712_2.

Zhou, F., Yu, T., Du, R., et al. (2020). Clinical course and risk factors for mortality of adult inpatients with COVID-19 in Wuhan, China: a retrospective cohort study. Lancet, S0140-6736(20), 30566-30573.

Publisher's Note Springer Nature remains neutral with regard to jurisdictional claims in published maps and institutional affiliations. 